\title{
The Effect of Bidet Use on Severity of Constipation and Quality of Life Among Pregnant Women
}

\author{
Sultan Alan,* Ebru Gozuyesil* and Sule Gokyildiz Surucu* \\ *Cukurova University, Faculty of Health Sciences, Midwifery Department, Adana, Turkey
}

\begin{abstract}
Background Constipation is a common problem in pregnancy. This study aims to elucidate the efficacy of using a bidet before defecation to reduce the severity of constipation and improve the quality of life in pregnancy.

Methods The sample consisted of an experimental group $(n=30)$ and a control group $(n=30)$, a total of 60 pregnant women. Randomization was performed using the pitch-and-toss method from simple probability randomization methods. The research data were collected using the Personal Information Form, the Constipation Assessment Scale for Pregnancy, and the Constipation Quality of Life Scale.
\end{abstract}

Results There was a statistically significant difference between the pregnant women's mean scores on the Constipation Assessment Scale for Pregnancy due to the intervention of bidet before defecation. Although the members of the intervention group had severe constipation at first, they reported only "some problems" on defecation after the intervention. In addition, statistically significant improvements were observed in the intervention group via all subscales of the Constipation Quality of Life Scale except the satisfaction subscale.

Conclusion Providing pregnant women with training on constipation and information about how to control constipation using a bidet is very important in terms of reducing the severity of constipation, enabling them to feel better and continue their daily activities, and thus to improve their quality of life.

Key words constipation; ease of defecation; pregnancy; quality of life

Constipation is one of the most common health issues across the world. It is seen in a significant proportion of individuals living in western societies and affects especially women, children, and the elderly. According

Corresponding author: Sultan Alan

tasalan@cu.edu.tr

Received 2020 May 22

Accepted 2020 July 31

Online published 2020 August 20

Abbreviations: CASP, Constipation Assessment Scale for Pregnancy; CQLS, Constipation Quality of Life Scale to the generally accepted view, constipation is described as having three or fewer bowel movements a week. The international Rome criteria prepared by the relevant experts are the most commonly used classifications to standardize the definition of constipation. According to the Rome criteria, constipation not only refers to fewer defecations but also is a complex syndrome with many symptoms. ${ }^{1,2}$ However, there is also a diagnosis system that is formed by a simplified set of criteria that can be used to diagnose constipation in pregnancy. Accordingly, constipation includes low frequency of stools ( $<3$ per week), hard stools, and/or difficulties in the evacuation of feces. ${ }^{3}$

Constipation is a common problem in pregnancy. Studies report the incidence of constipation in pregnancy as ranging between $11 \%$ and $38 \%{ }^{1,4,5}$ Studies also report that pregnant women are very susceptible to constipation in the first two trimesters. The prevalence of functional constipation has been reported as 35\% in the first trimester, $39 \%$ in the second trimester, $21 \%$ in the third trimester, and $17 \%$ in the puerperium. ${ }^{1}$

Studies report that increased progesterone levels in pregnancy produce relaxation in the intestinal smooth muscles, causing reduced gastrointestinal motility, and that this effect occurs most in the second and third trimesters. ${ }^{1,2}$ Relaxin is a hormone secreted in pregnancy that inhibits the contraction of the myometrium. Similar to progesterone, relaxin inhibits smooth muscle cells in the gastrointestinal tract. ${ }^{2}$ Increased water absorption in the colon is also a factor causing constipation in pregnancy. Studies on colon perfusion have shown that increased levels of aldosterone increase water absorption in pregnant women, leading to small, hardened stools symptoms. ${ }^{1,2,4}$ Estrogen and progesterone stimulate renin secretion. Renin causes angiotensinogen to be converted into angiotensin I, and then into angiotensin II. Later, angiotensin II causes an increase in aldosterone levels. In the late stages of pregnancy, the expanding uterus and growing fetus may also slow down the passage of food through the gut by directly compressing the gastrointestinal tract lumen. Pressure on the levatorani muscle, which forms part of the external anal sphincter and is an important muscle of evacuation, may cause damage during gestation and childbirth, leading to deterioration in defecation. ${ }^{1,2,4}$ In addition, 
insufficient consumption of fluid and fibrous foods and intake of drugs such as iron and magnesium sulphate during pregnancy contribute to these factors. ${ }^{1,4,6}$

Constipation is a health issue that negatively affects daily life activities and is frequently seen in pregnancy. Most women try to overcome this problem by increasing the amount of fibrous foods and liquid in their diets without using laxatives. ${ }^{1}$ However, this solution may be inadequate for some pregnant women with constipation.

There are two types of toilets commonly used in Turkey, called alla franca and allaturca. The alla franca lavatory pan, also known as a toilet bowl, which consists of a wall-hung WC pan with a cover. The allaturca lavatory pan (squat toilet) has a WC pan with a hole in the middle used for squatting rather than sitting. The architecture of Turkish houses usually includes both types of toilets. ${ }^{7}$ Because of traditional and religious beliefs, it is very common to wash (cleanse) and dry the anal region after defecation in Turkish society. The first type of toilet bowl in European countries did not have a bidet nozzle. In these countries, anal cleansing is done using toilet paper after defecation. However, bidet nozzles are added to toilet bowls used in Turkish society, where anal cleansing is usually performed using water. It is becoming popular in Western European countries to add a seat called a "bidet" to toilet bowls, which enables cleansing of the anal region with pressurized water after defecation. ${ }^{7}$ Studies report that bidet use facilitates defecation and personal hygiene. ${ }^{8-10}$

This study proposes a method that may enable easier defecation among individuals with constipation. The method aims to ease defecation, reduce severity of constipation, and improve quality of life in pregnant women by providing a water flow via a bidet to the anal region before defecation. Use of bidet toilets is quite common in Turkey. They are frequently used in almost every home by pregnant women and the elderly. No studies in literature seem to have investigated the effect of pre-defecation bidet use in reducing constipation; the present study is the first study focusing on this topic. Our aim in this study is to elucidate the efficacy of using a bidet before defecation to reduce the severity of constipation and improve the quality of life in pregnancy.

\section{MATERIALS AND METHODS Type of research}

This was a randomized controlled intervention study.

\section{Study population and sample}

The study population consisted of pregnant women who attended a pregnancy school in a healthy living center affiliated to the Ministry of Health. The study was conducted with intervention and control groups.
Randomization was performed using the pitch-andtoss method from simple probability randomization methods. The sample size was calculated by statistical power analysis using G*Power3.1 program. ${ }^{11}$ Twentyseven individuals were required per group under the assumptions that the difference between changes between two groups equal to half of the standard deviation is considered clinically significant (effect size $=0.5$ ). The significance level was $\alpha=0.05$, and the power was $1-\beta$ $=0.80$. If $10 \%$ of participants were placed as a substitute, it was appropriate to assign 30 pregnant women to each group. The inclusion criteria for pregnant women were as follows: having low frequency of stools $(<3$ per week), hard stools, and/or difficulties in evacuating feces at any gestational week; volunteering to participate in the study; not using a bidet for constipation before; and having adequate communication skills. Women with risky pregnancy (premature membrane rupture, threatened premature labor) were excluded from the study.

\section{Data collection tools}

The research data were collected using the Personal Information Form, the Constipation Assessment Scale for Pregnancy, and the Constipation Quality of Life Scale.

\section{Personal information form}

This form was prepared by the researchers in line with the literature and consisted of 13 questions about pregnant women's socio-demographic and obstetric characteristics.

\section{Simplified criteria for diagnosis of constipation in pregnancy}

The Rome III Diagnostic Criteria are used in routine clinical practice to diagnose constipation. However, instead of using these criteria to diagnose constipation in pregnancy, Cullen and O'Donoghue ${ }^{3}$ proposed a diagnosis system with the following simplified set of criteria;

1. Low frequency of stools $(<3 /$ week $)$

2. Hard stools

3. Difficulty in evacuation.

Accordingly, if a pregnant woman meets the first criterion (essential) and at least one of the others, then she is diagnosed with constipation. ${ }^{2,3}$

\section{Constipation Assessment Scale for Pregnancy (CASP)}

The scale was developed and its validity and reliability were performed by Susan C. McMillian and Faye A. Williams. ${ }^{12}$ The validity and reliability of the scale for 
pregnant women was verified by Brenda S. Broussard..$^{13}$ In Turkey, its validity and reliability for pregnant women was performed by Gündüz and Demirci. ${ }^{14}$ The scale determined eight characteristic signs of constipation: abdominal distention or bloating, change in the amount of gas passed rectally, less frequent bowel movements, oozing liquid stool, rectal fullness or pressure, rectal pain with bowel movements, small volume of stool, and urge but inability to pass stool. A three-point summated rating scale was constructed $(0=$ no problem, $1=$ some problem, 2 = severe problem). However, unlike the rating scale developed by Susan C. McMillian and Faye A. Williams, Gündüz and Demirci (2002) constructed a five-point summated rating scale $(0=$ no problem, $1=$ very little problem, $2=$ some problem, $3=$ some severe problem, $4=$ severe problem). The total score on the scale ranges between 0 and 32. According to the total score obtained, four classifications are made: $0-8$ points $=$ no problem $/$ very little problem, $9-16$ points $=$ some problem, $17-24=$ some problem/some severe problem, $25-32=$ some severe problem $/$ severe problem. ${ }^{14}$

\section{Constipation Quality of Life Scale (CQLS)}

The scale was developed by Marquis et al., ${ }^{15}$ and its validity and reliability study for the Turkish context was performed by Dedeli et al. ${ }^{16}$ The scale's Cronbach's alpha reliability coefficient and test-retest reliability were found to be 0.91 and 0.96 , respectively $(P<0.01)$. This is a 28-item self-assessment scale consisting of four subscales: "anxiety (worries and concerns)" (11 items), "physical discomfort" (four items), "psychosocial discomfort" (8 items), and "satisfaction" (5 items). The items of this five-point Likert-type scale are scored from 1 to 5 . Respondents assess the items in the first and fifth sections of the scale as follows: "not at all (1)," "a little bit (2)," "moderately (3)," "quite a bit (4)," and "extremely (5)," and the items in the second, third, fourth, and sixth sections of the scale as follow; "none of the time (1) ", "a little of the time (2)," "some of the time (3)," "most of the time (4)," and "all of the time (5)." The highest and lowest scores on the scale are 140 and 28, respectively. Higher scores represent poorer quality of life. As the scores of the scale increase, the quality of life is thought to be adversely affected. All items should be answered to code the score obtained. ${ }^{16}$

\section{Data collection}

\section{Intervention group method}

This study proposed a method that is expected to enable pregnant women with constipation more comfortable defecation.

\section{Intervention group intervention}

- The personal information form, CASP, and the CQLS were administered to the pregnant women in the intervention group.

- The participants were asked to use a bidet for 2-5 minutes before each defecation and to continue this intervention for 7 days.

- The participants were called by phone three days a week and were encouraged to continue with the intervention.

- The CASP and the CQLS were readministered after 7 days of the intervention.

\section{Control group intervention}

- The personal information form, the Constipation Assessment Scale for Pregnancy, and the Constipation Quality of Life Scale were administered to the pregnant women in the control group.

- No intervention was done.

- The Constipation Assessment Scale for Pregnancy, and the Constipation Quality of Life Scale were readministered after 7 days.

After the second administration of the forms, this group received the same training provided to the intervention group in order to give them some benefit from the intervention (Fig. 1).

\section{Data evaluation}

The data obtained were calculated using SPSS (statistical program for social science) 22 for Windows (IBM, Armonk, NY) and analyzed through frequency, mean, standard deviation, median, minimum, maximum, student's $t$-test, and paired $t$-test.

\section{Ethical considerations}

Ethical approval was obtained from the Faculty of Medicine Ethics Committee of the university (Date: 02.02.2018; Permission no: 2018/74/26). In addition, informed consent was obtained from the individuals who participated in the study.

\section{RESULTS}

Roughly a third of the participants (35\%) had a university degree, $50 \%$ were employed, $88.3 \%$ had social security, $66.7 \%$ had middle-income, $85 \%$ had a nuclear family, and 50\% had children (Table 1).

In the intervention group, the mean age was 29.73 \pm 5.13 years $(\min 21, \max 41)$, they had been married for $6.23 \pm 5.11$ years on average, the mean number of pregnancies was $2.00 \pm 1.287$, and the mean gestational week was $27.33 \pm 4.67$. In the control group, the mean age was $29.90 \pm 5.054$ years, they had been married 
A sample was selected from among pregnant women who met the study inclusion criteria and had similar socio-demographic characteristics.

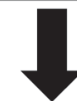

A personal information form, CASP, and CQLS were administered to all participants.

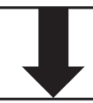

Intervention and control groups were assigned randomly (30 individuals in each group)

\section{Intervention Group $(n=30)$}

Pregnant women were asked to use a bidet toilet for 2-5 minutes before each defecation and to continue this intervention for 7 days.

\section{Control Group $(\boldsymbol{n}=\mathbf{3 0})$}

No intervention was made.

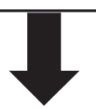

The CASP and CQLS were administered simultaneously to both groups.

Fig. 1. Research process flow chart.

for $5.43 \pm 3.73$ years on average, the mean number of pregnancies was $2.10 \pm 0.92$, and the mean gestational week was $24.13 \pm 5.83$. The pregnant women in the intervention and control groups were similar in terms of demographic and obstetric characteristics (Table 1).

The intervention and control groups had similar outcomes before the intervention; however, there was a statistically significant difference between the groups' posttest CASP mean scores $(P<0.001, P=0.23)$. The mean score of CASP significantly dropped after intervention $(26.00 \pm 5.48$ to14.66 $\pm 3.29, P<0.001)$ (Fig. $2 \mathrm{~A})$. Regarding the mean scores on subscales of the CQLS, the experimental and control groups had similar results on all the subscales before the intervention. The subscales, "anxiety", "physical discomfort" and "psychosocial discomfort" were significantly decreased after the intervention $(25.77 \pm 7.94$ to $13.20 \pm 5.35, P<0.05$; $10.03 \pm 2.56$ to $4.27 \pm 2.40, P<0.05 ; 15.23 \pm 6.07$ to 5.73 $\pm 4.33, P<0.05$; respectively). However, these subscales did not change in the control groups $(20.77 \pm 7.40$ to
$24.23 \pm 12.58, P=0.02 ; 10.30 \pm 3.31$ to $11.20 \pm 4.45, P<$ $0.001 ; 12.13 \pm 5.27$ to $15.13 \pm 10.32, P=0.004$; respectively) (Figs. 2B, C and D). The subscale "satisfaction" was maintained in the experimental group $(12.00 \pm 3.24$ to $12.87 \pm 1.73, P=0.246$ ); however, it was significantly decreased in the control group $(11.30 \pm 2.95$ to $9.17 \pm 2.27$, $P=0.028)$ (Fig. 2E).

\section{DISCUSSION}

In this study, we elucidated that using a bidet before defecation improved the CASP and the mean scores of the three subscales of CQLS significantly. The telephone calls aimed solely to remind the education. They included no additional information or consultancy in order to prevent any bias.

Constipation is a common health issue in pregnancy. The present study found that $66.5 \%$ of the pregnant women with constipation were in the second trimester and $50 \%$ were multiparous. Studies report that constipation is more frequent in the first and second trimesters 
Table 1. Participants' demographic and obstetrical characteristics

\begin{tabular}{|c|c|c|c|c|}
\hline Demographic Characteristics & $\begin{array}{c}\text { Intervention } \\
n(\%)\end{array}$ & $\begin{array}{c}\text { Control } \\
n(\%)\end{array}$ & $\begin{array}{l}\text { Total } \\
n(\%)\end{array}$ & $P$ \\
\hline \multicolumn{5}{|l|}{ Age (years) } \\
\hline 20-29 & $15(50.0)$ & $12(40.0)$ & $27(45.0)$ & \multirow[t]{3}{*}{$0.73^{*}$} \\
\hline $30-34$ & $10(33.3)$ & $12(40.0)$ & $22(36.6)$ & \\
\hline 35 and over & $5(16.7)$ & $6(20.0)$ & $11(18.4)$ & \\
\hline \multicolumn{5}{|l|}{ Education } \\
\hline Literate & $2(6.7)$ & $0(0.0)$ & $2(3.3)$ & \multirow[t]{5}{*}{$0.17^{*}$} \\
\hline Primary school & $2(6.7)$ & $8(26.7)$ & $10(16.7)$ & \\
\hline Middle school & $8(26.7)$ & $6(20.0)$ & $14(23.3)$ & \\
\hline High school & $6(20.0)$ & $7(23.3)$ & $13(21.7)$ & \\
\hline University and above & $12(40.0)$ & $9(30.0)$ & $21(35)$ & \\
\hline \multicolumn{5}{|l|}{ Employment status } \\
\hline Employed & $16(53.3)$ & $14(46.7)$ & $30(50)$ & \multirow[t]{2}{*}{$0.60 \dagger$} \\
\hline Unemployed & $14(46.7)$ & $16(53.3)$ & $30(50)$ & \\
\hline \multicolumn{5}{|l|}{ Social security } \\
\hline Yes & $26(86.7)$ & $27(90.0)$ & $53(88.3)$ & \multirow[t]{2}{*}{$0.50 \dagger$} \\
\hline No & $4(13.3)$ & $3(10.0)$ & $7(11.7)$ & \\
\hline \multicolumn{5}{|l|}{ Perceived income level } \\
\hline Poor & $5(16.7)$ & $2(6.7)$ & $7(11.7)$ & \multirow[t]{3}{*}{$0.19^{*}$} \\
\hline Middle & $21(70.0)$ & $19(63.3)$ & $40(66.7)$ & \\
\hline Good & $4(13.3)$ & $9(30.3)$ & $13(21.7)$ & \\
\hline \multicolumn{5}{|l|}{ Type of family } \\
\hline Nuclear family & $27(90.0)$ & $24(80)$ & $51(85.0)$ & \multirow[t]{2}{*}{$0.47 \dagger$} \\
\hline Extended family & $3(10.0)$ & $6(20)$ & $9(15.0)$ & \\
\hline \multicolumn{5}{|l|}{ Place of childhood } \\
\hline City & $26(86.7)$ & $21(70.0)$ & $47(78.3)$ & \multirow[t]{3}{*}{$0.09^{*}$} \\
\hline Town & $0(0.0)$ & $4(13.3)$ & $4(6.7)$ & \\
\hline Village & $4(13.3)$ & $5(16.7)$ & $9(15.0)$ & \\
\hline \multicolumn{5}{|l|}{ Gestational week } \\
\hline $0-14$ & $1(3.3)$ & $2(6.7)$ & $3(5.0)$ & \multirow[t]{3}{*}{$0.03 *$} \\
\hline $15-28$ & $16(53.3)$ & $24(80.0)$ & $40(66.5)$ & \\
\hline $29-40$ & $13(43.3)$ & $4(13.3)$ & $17(28.3)$ & \\
\hline \multicolumn{5}{|l|}{ Number of pregnancies } \\
\hline $1-3$ & $28(93.3)$ & $28(93.3)$ & $56(93.3)$ & \multirow[t]{2}{*}{$0.69 \dagger$} \\
\hline 4 and over & $2(6.7)$ & $2(6.7)$ & $4(6.7)$ & \\
\hline \multicolumn{5}{|l|}{ Number of children } \\
\hline 0 & $18(60.0)$ & $12(40.0)$ & $30(50.0)$ & \multirow[t]{3}{*}{$0.07^{*}$} \\
\hline $1-3$ & $10(33.3)$ & $18(60.0)$ & $28(46.7)$ & \\
\hline 4 and over & $2(6.7)$ & $0(0.0)$ & $2(3.3)$ & \\
\hline \multicolumn{5}{|l|}{ Duration of marriage } \\
\hline $1-5$ years & $18(60.0)$ & $18(60.0)$ & $36(60.0)$ & $0.71^{*}$ \\
\hline $6-10$ years & $6(20.0)$ & $8(26.7)$ & $14(23.3)$ & \\
\hline 10 years and above & $6(20.0)$ & $4(13.3)$ & $10(16.7)$ & \\
\hline Husband's education level & & & & \\
\hline Literate & $0(0.0)$ & $0(0.0)$ & $0(0.0)$ & $0.60^{*}$ \\
\hline Primary school & $0(0.0)$ & $1(3.3)$ & $1(1.7)$ & \\
\hline Middle school & $5(16.7)$ & $6(20.0)$ & $11(18.3)$ & \\
\hline High school & $9(30.0)$ & $11(36.7)$ & $20(33.3)$ & \\
\hline University and above & $16(53.3)$ & $12(40.0)$ & $28(46.7)$ & \\
\hline Husband's employment status & & & & \\
\hline Employed & $30(100.0)$ & $28(93.3)$ & $58(96.7)$ & $0.24 \dagger$ \\
\hline Unemployed & $0(0.0)$ & $2(6.7)$ & $2(3.3)$ & \\
\hline
\end{tabular}

*One-way ANOVA Test, †Student's $t$-test 
A

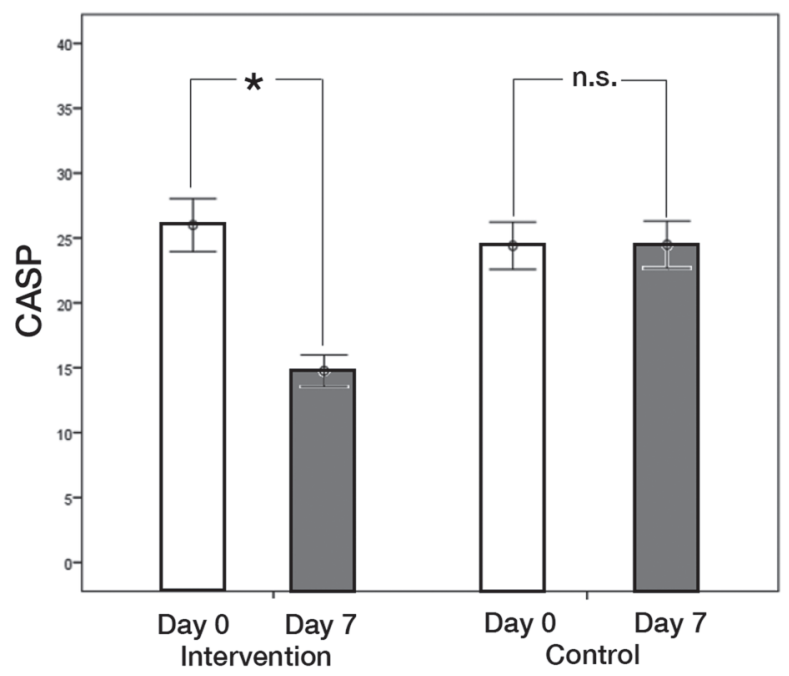

C

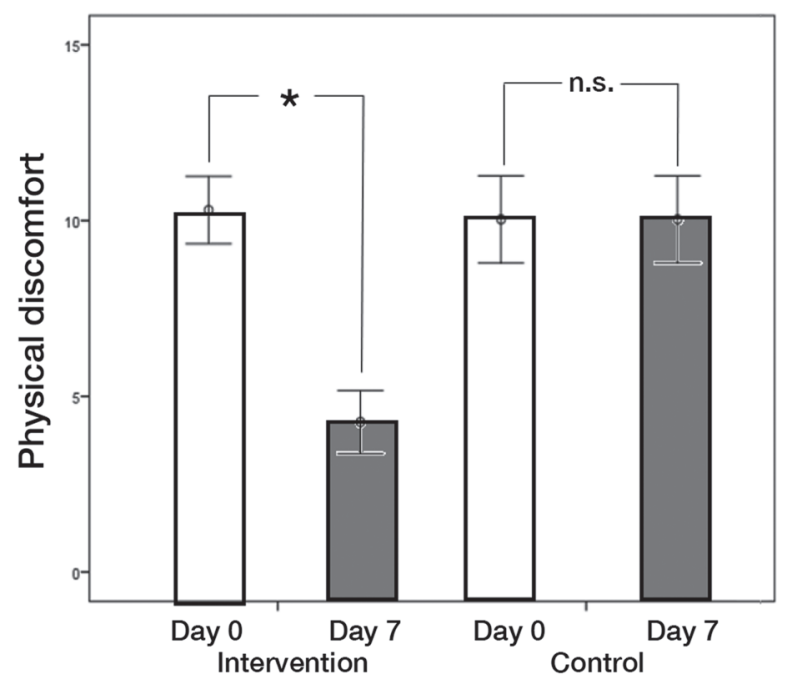

E

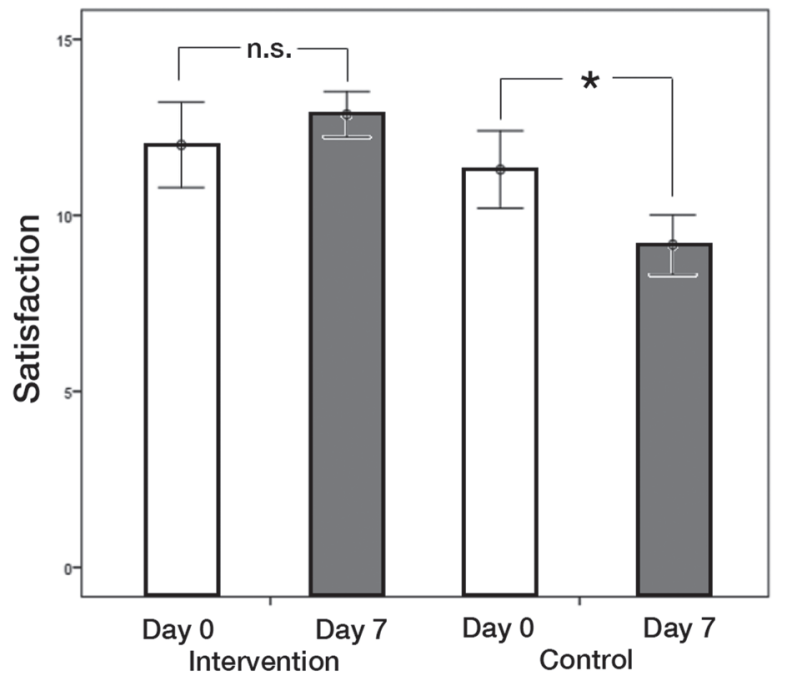

B

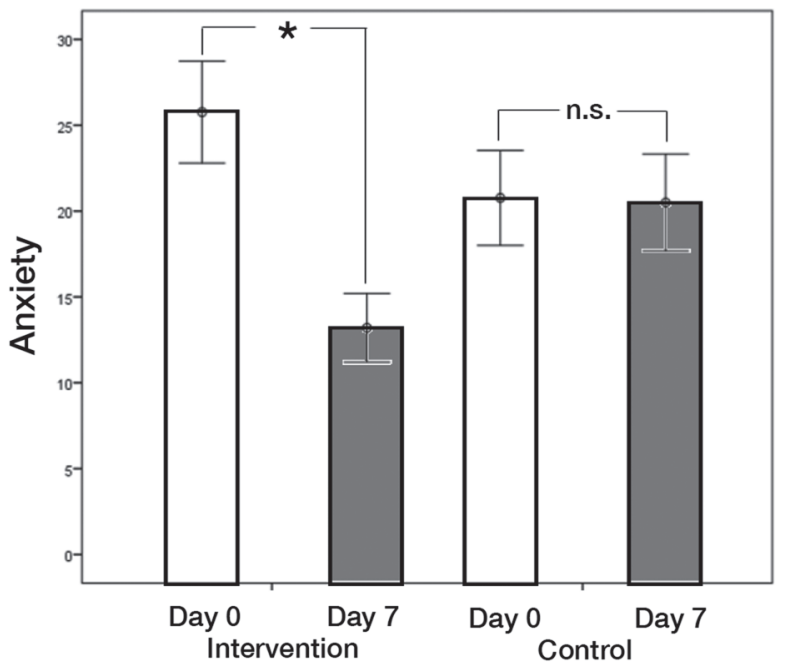

D

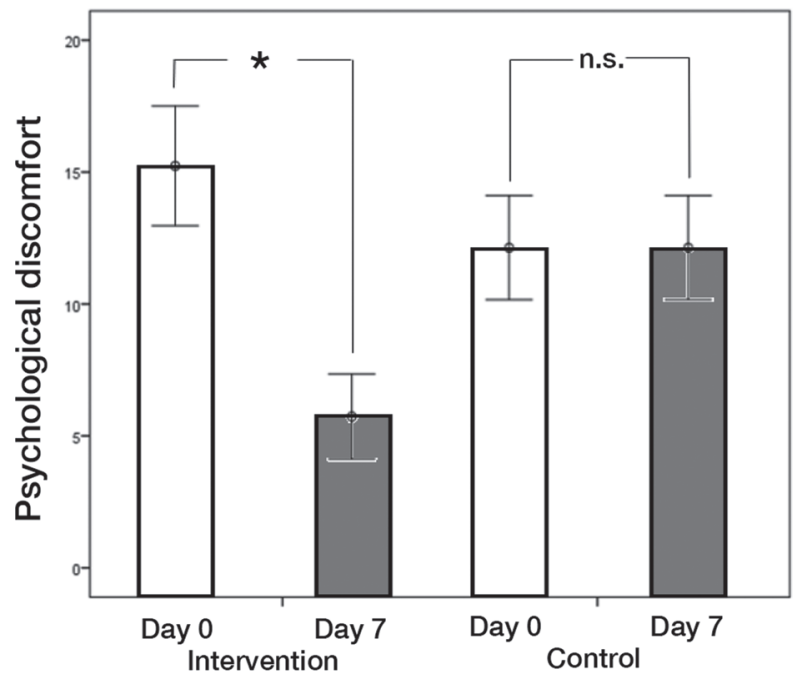

Fig. 2. Evaluation of the participants' CASP and CQLS total and subscales scores in intervention and control groups. A: Means of CASP scores, B: Means of CQLS of anxiety subscale scores, $\mathbf{C}$ : Means of CQLS of physical discomfort subscale scores, D: Means of CQLS of psychosocial discomfort subscale scores, E: Means of CQLS of satisfaction subscale scores. Error bars indicate 95\% confidence intervals. ${ }^{*} P<0.050$. n.s., not significant. 
of pregnancy and among multiparous pregnant women. The prevalence of constipation in pregnancy ranges approximately between $11 \%$ and $38 \%,{ }^{1,4} 35 \%$ in the first trimester, $39 \%$ in the second trimester, and $21 \%$ in the third trimester. ${ }^{1}$ Kaya reported that $41.7 \%$ of pregnant women with constipation were in the second trimester. The present study's results are thus similar to those in the literature. ${ }^{17}$

There was a statistically significant difference between the intervention group's pre- and posttest CASP mean scores, and their mean score dropped significantly after the intervention $(P<0.001)$ In other words, the pretest scale mean score indicated severe constipation among pregnant women in the intervention group before the intervention; however, this problem changed into "some problem" after the intervention; namely, the severity of constipation decreased in the intervention group while there was no change in the control group. The results of the present study suggest that the intervention of using a bidet to the anal region before defecation eases defecation and reduces the severity of constipation in pregnant women.

The recommended practices for reducing the severity of constipation during pregnancy are often to increase the amount of fibrous food and fluid intake, to exercise, and thus to overcome the problem without taking laxatives. ${ }^{1,18}$ However, this solution may be inadequate to provide benefits for some pregnant woman with constipation. Pharmacological interventions are recommended when non-pharmacological interventions fail. ${ }^{18}$ Providing water flow to the anal region via bidet nozzle softens anal tissue and eases defecation by creating a massage effect on anal tissue. This intervention can be an effective method of easing the defecation of individuals in their own homes paying attention to hygiene rules.

Tsunoda et al. conducted a survey of electric bidet toilet use among community-dwelling Japanese people and correlated for an itch on the anus, and reported that $83 \%$ of 4963 respondents had a bidet toilet at home, $55 \%$ used these toilets, and at least $30 \%$ used the bidet before defecation to ease the process. As for the reasons for washing the anus before defecation, $70 \%$ of the respondents reported that it aided defecation by stimulating the anus with a jet of water, and $20 \%$ reported that it aided defecation like an enema when water penetrates the rectum. ${ }^{19}$ Hongoh et al. reported that $41.3 \%$ of 305 women who participated in the study washed the anal region for induction of defecation. ${ }^{8}$ Uchikawa et al. reported that use of a washing toilet seat successfully induced bowel movements in patients with spinal cord injury. ${ }^{7}$ Another study reported that bidet use increased anal resting pressure. ${ }^{9}$ As the above shows, providing water flow to the anal region via bidet can be effective in reducing the severity of constipation.

Beside the effect of bidet toilet use in relieving constipation, studies also report that the use of these toilets in public areas has some risks, and that the water nozzles of bidet toilets are contaminated with a wide range of bacteria, especially in hospitals, making them a potential vehicle for cross-infection. ${ }^{20,21} \mathrm{Kim}$ et al. conducted a study of high-risk pregnant women with preterm labor and reported that the use of a bidet toilet was associated with abnormal vaginal colonization and increased the rate of preterm labor in high-risk pregnancies. ${ }^{21}$ Ogino et al. conducted a study with 268 non-pregnant women of reproductive age and reported that habitual use of bidet toilets aggravated vaginal microflora, either by depriving normal microflora or facilitating opportunistic infection of fecal bacteria and other microorganisms. ${ }^{22}$ Unlike these studies, Asakura et al. examined the effect of bidet toilet use on preterm birth and vaginal flora in pregnant women with the participation of 2545 women who gave birth between 2006 and 2010 in Tokyo and reported that normal use of the bidet toilet by pregnant women posed no clinical health risk for preterm birth and bacterial vaginosis. ${ }^{23}$ Kiuchi et al. conducted a one-year follow-up web survey to examine bidet toilet use and the incidence of hemorrhoids or urogenital infections. They found that hemorrhoids and urogenital infections were not causally related to habitual bidet toilet use and reported that individuals with anal and genital discomfort may prefer to use a bidet toilet. ${ }^{24}$ If attention is paid to hygiene rules, the use of bidet toilets may safely ease defecation and increase comfort in defecation. It is very common to wash (cleanse) and dry the anal region after defecation in Turkish society because of traditional and religious beliefs. All bidet toilets in Turkey have a nozzle providing water flow.

Constipation is an important health issue for both individuals and society. It is common across the world, reduces quality of life, causes burnout and loss of labor force, increases healthcare costs, and has negative effects on health status. ${ }^{25}$ Constipation is also a common health issue in pregnancy. It has various consequences that affect the perception of physical health and quality of life in pregnant women. ${ }^{18}$ Johonson et al. conducted a study to measure the effect of constipation on quality of life in pregnant women and found that pregnant women with intestinal problems had lower quality of life. ${ }^{26}$ Kaya determined that pregnant women with constipation obtained lower scores on all subscales of the CQLS than those without constipation. ${ }^{17}$ Belsey et 
al. found that constipation affected the quality of life in $52 \%$ of 557 constipation patients of all ages. ${ }^{27}$ Similar studies have also shown that constipation affects quality of life negatively. ${ }^{28}$ The present study found that after the intervention of water flow, physical discomfort, psychosocial discomfort, and anxiety levels dropped significantly among pregnant women in the intervention group $(P<0.05)$. Also, it may not be said that the difference observed in the sub-dimension of satisfaction between the experimental and control groups after bidet use occurred due to the use of bidet.

There are a limited number of intervention studies on the relief of constipation during pregnancy. Some suggest that massage may have a positive effect on relieving constipation. ${ }^{29-31}$

Considering that the method used in this study had a massage effect on tissue in the anal region, this effect may have contributed to the positive results obtained. In addition to its contribution to easing defecation in pregnant women with constipation, the method can be effective in improving their quality of life.

According to the results of the present study, the intervention of water flow to the anal region via bidet before defecation caused significant difference between the intervention and control groups' mean scores on the CASP. Pregnant women in the intervention group had severe constipation at first, but reported only "some problem" after the intervention. However, the control group experienced no change. In addition, statistically significant improvements were observed in the intervention group on all subscales of the CQLS except the satisfaction subscale.

Constipation, one of the most common complaints of pregnant women, is preventable. In the antenatal period, besides the nutrition and exercise training, the information about using a bidet to decrease the severity of constipation is also highly valuable. It will help them feel better, and maintain their daily activities, and thus improve their quality of life.

In conclusion, using a bidet decreased the constipation severity, constipation-related physical and psychosocial discomfort and anxiety. Use of bidet is a reliable method that enables easy and comfortable defecation in pregnant women as long as hygiene rules are followed.

Acknowledgments: We would like to express our gratitude to Adana Maternity and Children Hospital delivery team members, and all the pregnant women who accepted to participate in the study.

The authors declare no conflicts of interest.

\section{REFERENCES}

1 Verghese TS, Futaba K, Latthe P. Constipation in pregnancy. Obstet Gynaecol. 2015;17:111-5. DOI: 10.1111/tog.12179

2 Aygün C, Aygün B. [Pregnancy and constipation]. Journal of İnönü University Medical Faculty. 2010;17:71-5. Turkish.

3 Cullen G, O’Donoghue D. Constipation and pregnancy. Best Pract Res Clin Gastroenterol. 2007;21:807-18. DOI: 10.1016/ j.bpg.2007.05.005, PMID: 17889809

4 Trottier M, Erebara A, Bozzo P. Treating constipation during pregnancy. Can Fam Physician. 2012;58:836-8. PMID: 22893333

5 Seltzer R. Evaluation and diagnosis of constipation. Gastroenterol Nurs. 2012;35:343-8. DOI: 10.1097/ SGA.0b013e31826b16al, PMID: 23018170

6 Vazquez JC. Constipation, haemorrhoids, and heartburn in pregnancy. BMJ Clin Evid. 2010:1411.

7 Yilmaz S. [Toilet culture in Turkish society: The example of Karabük]. Toplum Bilimleri Dergisi. 2011;5:90. Turkish.

8 Hongoh S, Usui Y, Inatuchi H, Fujisaki A, Kinjo M, Yoshimura Y, et al. The user fact-finding on the electric warm-water lavage toilet seats in the women consulting our urological outpatient clinic. Hinyokika Kiyo. 2016;62:53-6. PMID: 27018405

9 Uchikawa K, Takahashi H, Deguchi G, Liu M. A washing toilet seat with a CCD camera monitor to stimulate bowel movement in patients with spinal cord injury. Am J Phys Med Rehabil. 2007;86:200-4. DOI: 10.1097/ PHM.0b013e3180320edf, PMID: 17314704

10 Ryoo S, Song YS, Seo MS, Oh HK, Choe EK, Park KJ. Effect of electronic toilet system (bidet) on anorectal pressure in normal healthy volunteers: influence of different types of water stream and temperature. J Korean Med Sci. 2011;26:717. DOI: 10.3346/jkms.2011.26.1.71, PMID: 21218033

11 Faul F, Erdfelder E, Lang AG, Buchner A. G*Power 3: A flexible statistical power analysis program for the social, behavioral, and biomedical sciences. Behav Res Methods. 2007;39:175-91. DOI: 10.3758/BF03193146, PMID: 17695343

12 McMillan SC, Williams FA. Validity and reliability of the constipation assessment scale. Cancer Nurs. 1989;12:183-8. DOI: 10.1097/00002820-198906000-00012, PMID: 2743302

13 Broussard BS. The constipation assessment scale for pregnancy. J Obstet Gynecol Neonatal Nurs. 1998;27:297-301. DOI: 10.1111/j.1552-6909.1998.tb02652.x, PMID: 9620822

14 Gündüz G. [Evaluation of constipation in pregnancy] [dissertation]. Istanbul: Marmara University Institute of Health Sciences; 2002. Turkish.

15 Marquis P, De La Loge C, Dubois D, McDermott A, Chassany O. Development and validation of the patient assessment of constipation quality of life. Scand J Gastroenterol. 2005;40:540-51. DOI: 10.1080/00365520510012208, PMID: 16036506

16 Dedeli Ö, Turan İ, Fadıloğlu C, Bor S. [Validity and reliability study of the constipation quality of life scale]. MN dahili tıp bilimleri. 2007;2:36-43. Turkish.

17 Kaya R. [Constipation in pregnancy and its relationship with quality of life] [dissertation]. Aydın (Turkey): Aydın Adnan Menderes University; 2018. Turkish.

18 Rungsiprakarn P, Laopaiboon M, Sangkomkamhang US, Lumbiganon P, Pratt JJ. Interventions for treating constipation in pregnancy. Cochrane Database Syst Rev. 2015;CD011448. DOI: 10.1002/14651858.CD011448.pub2, PMID: 26342714 
19 Tsunoda A, Takahashi T, Arika K, Kubo S, Tokita T, Kameda S. Survey of electric bidet toilet use among community dwelling Japanese people and correlates for an itch on the anus. Environ Health Prev Med. 2016;21:547-53. DOI: 10.1007/ s12199-016-0578-3, PMID: 27714679

20 Kanayama Katsuse A, Takahashi H, Yoshizawa S, Tateda K, Nakanishi Y, Kaneko A, et al. Public health and healthcareassociated risk of electric, warm-water bidet toilets. J Hosp Infect. 2017;97:296-300. DOI: 10.1016/j.jhin.2017.07.021, PMID: 28756169

21 Kim YM, Kim JY, Lee MY, Choi SJ, Oh S, Shim JY, et al. Prospective study of bidet toilet use: association of abnormal vaginal colonization and preterm birth in high-risk pregnant women. J Obstet Gynaecol Res. 2019;45:1134-42. DOI: 10.1111/jog.13953, PMID: 30884065

22 Ogino M, Iino K, Minoura S. Habitual use of warm-water cleaning toilets is related to the aggravation of vaginal microflora. J Obstet Gynaecol Res. 2010;36:1071-4. DOI: 10.1111/ j.1447-0756.2010.01286.x, PMID: 21058441

23 Asakura K, Nakano M, Yamada M, Takahashi K, Sueoka K, Omae K. Effect of bidet toilet use on preterm birth and vaginal flora in pregnant women. Obstet Gynecol. 2013;121:118794. DOI: 10.1097/AOG.0b013e318291bc16, PMID: 23812451

24 Kiuchi T, Asakura K, Nakano M, Omae K. Bidet toilet use and incidence of hemorrhoids or urogenital infections: A oneyear follow-up web survey. Prev Med Rep. 2017;6:121-5. DOI: 10.1016/j.pmedr.2017.02.008, PMID: 28316906

25 Olgun S. [Abdominal massage intervention in constipation management]. Journal of Ege University Nursing Faculty. 2016;32:118-26. Turkish.
26 Johnson P, Mount K, Graziano S. Functional bowel disorders in pregnancy: effect on quality of life, evaluation and management. Acta Obstet Gynecol Scand. 2014;93:874-9. DOI: 10.1111/aogs.12434, PMID: 24862106

27 Belsey J, Greenfield S, Candy D, Geraint M. Systematic review: impact of constipation on quality of life in adults and children. Aliment Pharmacol Ther. 2010;31:938-49. DOI: 10.1111/j.1365-2036.2010.04273.x, PMID: 20180788

28 Wald A, Scarpignato C, Kamm MA, Mueller-Lissner S, Helfrich I, Schuijt C, et al. The burden of constipation on quality of life: results of a multinational survey. Aliment Pharmacol Ther. 2007;26:227-36. DOI: 10.1111/j.13652036.2007.03376.x, PMID: 17593068

29 Ayaş S, Leblebici B, Sözay S, Bayramoğlu M, Niron EA. The effect of abdominal massage on bowel function in patients with spinal cord injury. Am J Phys Med Rehabil. 2006;85:9515. DOI: 10.1097/01.phm.0000247649.00219.c0, PMID: 17117000

30 Lämås K, Lindholm L, Stenlund H, Engström B, Jacobsson C. Effects of abdominal massage in management of constipation-A randomized controlled trial. Int J Nurs Stud. 2009;46:759-67. DOI: 10.1016/j.ijnurstu.2009.01.007, PMID: 19217105

31 McClurg D, Walker K, Aitchison P, Jamieson K, Dickinson L, Paul L, et al. Abdominal massage for the relief of constipation in people with Parkinson's: A qualitative study. Parkinsons Dis. 2016;2016:4842090. DOI: 10.1155/2016/4842090, PMID: 28090363 